\title{
Inter ENSO variability and its influence over the South American monsoon system
}

\author{
A. R. M. Drumond and T. Ambrizzi \\ Institute of Astronomy, Geophysics and Atmospheric Sciences, Rua do Matao, 1226 Sao Paulo, Brazil \\ Received: 13 May 2005 - Revised: 13 January 2006 - Accepted: 16 January 2006 - Published: 1 February 2006
}

\begin{abstract}
Previous studies have discussed the interannual variability of a meridional seesaw of dry and wet conditions over South America (SA) associated to the modulation of the South Atlantic Convergence Zone (SACZ). However, they did not explore if the variability inter ENSO (El Niño Southern Oscillation) can be related to the phase changes of this dipole. To answer this question, an observational work was carried out to explore the atmospheric and Sea Surface Temperature (SST) conditions related to the same ENSO signal and to opposite dipole phases.

Rotated Empirical Orthogonal Function (REOF) analysis was applied over normalized Chen precipitation seasonal anomalies in order to find the dipole mode in the Austral Summer (December to February). The fourth rotated mode, explaining $6.6 \%$ of the total variance, consists of positive loading over the SACZ region and negative loading over northern Argentina. Extreme events were selected and enhanced activity of SACZ during the Summer season $(\mathrm{SACZ}+)$ was identified in nine years: five during La Niña events (LN) and two in El Niño episodes (EN). On the other hand, inhibited manifestations of this system (SACZ-) were identified in seven years: four in EN and two during LN.

Power spectrum analysis indicated that the interannual variability of the precipitation dipole seems to be related to the low frequency and to the quasi-biennial part of ENSO variability. The ENSO events with the same signal can present opposite phases for the dipole. The results suggest that the displacement of the convection over Indonesia and western Pacific can play an important role to modulate the seesaw pattern.
\end{abstract}

Correspondence to: A. R. M. Drumond

(anitadru@model.iag.usp.br)

\section{Introduction}

Nogués-Paegle and Mo (2002) suggested the existence of a precipitation dipole pattern over South America in the interannual variability. During enhanced activity of South Atlantic Convergence Zone (SACZ) events, there is a maximum of precipitation over its domain region and a minimum over the subtropics. The opposite occurs during the reduction of SACZ activity.

The modulation of the SACZ events and the Austral Summer South American precipitation can be influenced by SST variability. Several works have verified the influence of ENSO events over the South American precipitation (Grimm et al., 1998; and others). However, these works did not explore if the variability inter ENSO is related to the phase changes of the dipole pattern and how its mechanism work. To answer this question, the inter ENSO variability related to this low frequency South American dipole variability mode is studied.

\section{Data and Methods}

Chen et al. (2002) $2.5^{\circ}$ monthly precipitation anomalies were used in the REOF analysis. The National Center for Environmental Prediction (NCEP) Reanalysis $2.5^{\circ}$ atmospheric dataset (Kalnay et al., 1996) and the $2^{\circ}$ Reynolds and Smith (2004) SST data were used for the composites.

REOF analysis was applied over the normalized precipitation seasonal anomalies observed during 1950-2001 in order to find the dipole mode in the Austral Summer (from December to February). The domain is located between $60^{\circ} \mathrm{S}-$ $15^{\circ} \mathrm{N}$ and $30^{\circ} \mathrm{W}-90^{\circ} \mathrm{W}$. Applying the O'Lenic and Livezey (1988) criteria, the first eight precipitation modes obtained via EOF were rotated using the Varimax method. The fourth rotated mode (which explains $6.6 \%$ of the total variance) consists of positive loading over SACZ region and negative loading over northern Argentina. Extremes events were selected by applying a threshold of one standard deviation over 

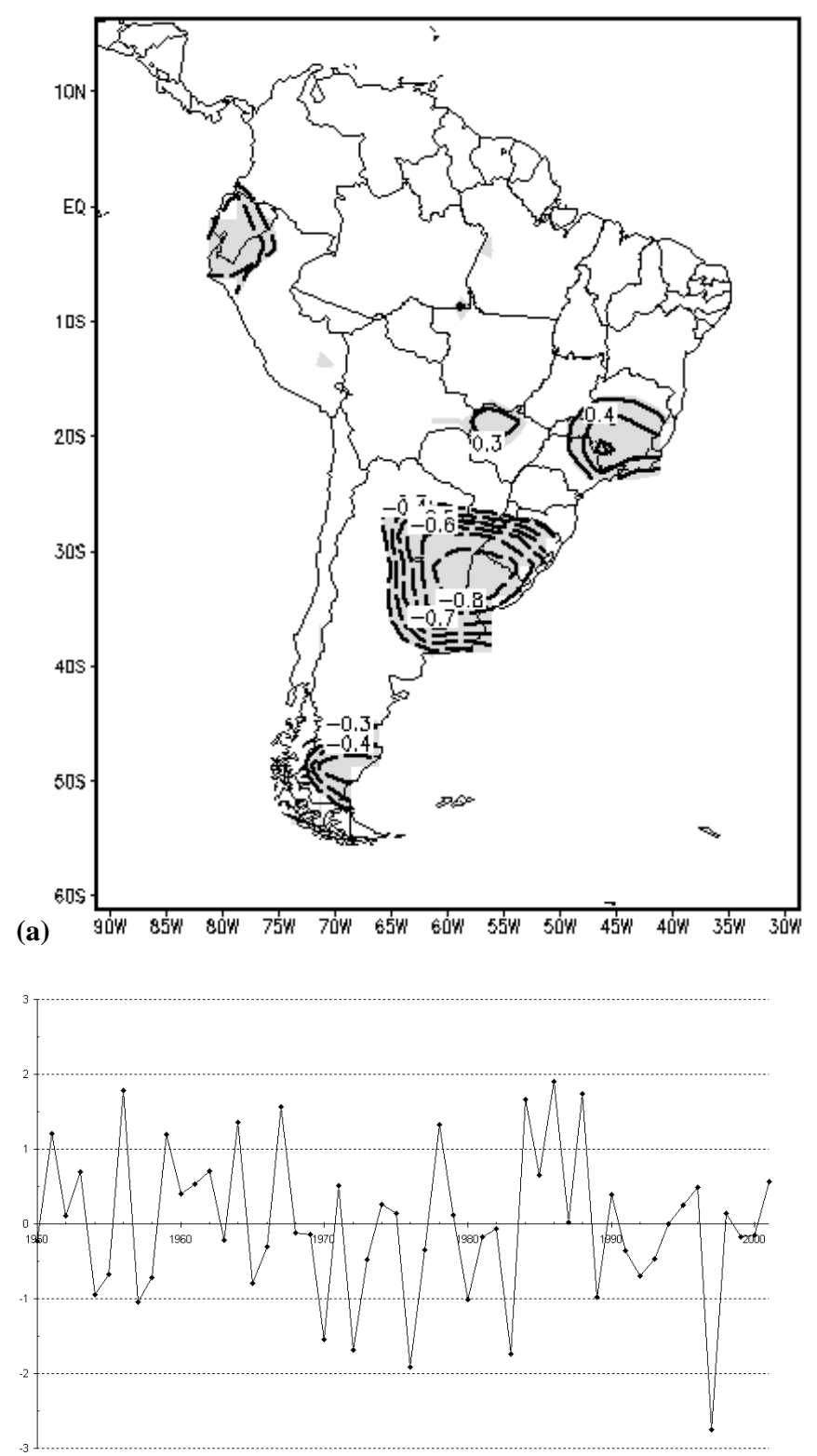

(b)

Fig. 1. (a) Correlation map between the 4 th rotated mode $(6.6 \%$ of the total variance) and the DJF precipitation anomalies over the South America. Gray areas indicate regions where the correlation is significant at the $95 \%$ level. Only isolines with absolute value higher than 0.3 are showed, using a 0.1 interval. Positive (negative) values are represented by continued (hashed) lines. (b) Associated normalized PC temporal series.

its normalized Principal Component time series (PC). The extreme events were classified according to the ENSO Trenberth (1997) criteria and composites were elaborated for four classes: La Niña events with enhanced and inhibited precipitation activity over the SACZ region (LN/SACZ+ and LN/SACZ-) and El Niño events with enhanced and inhibited precipitation activity over the SACZ region (EN/SACZ+ and $\mathrm{EN} / \mathrm{SACZ}-$ ).

\section{Results}

The correlation map between the 4 th mode (explaining $6.6 \%$ of the total variance) and the temporal series of the precipitation anomalies presents a dipolar structure with positive values over southeastern Brazil and negatives ones over northern Argentina (Fig. 1a). Through the PC temporal series (Fig. 1b), nine events presenting positive precipitation anomalies over southeastern Brazil and drought over the subtropics (SACZ+ events) were selected. Five SACZ+ events occurred during La Niña episodes (1956/57, 1964/65, 1967/68, 1984/85, 1988/89), while two occurred during El Niño episodes $(1951 / 52,1986 / 87)$. On the other hand, two SACZ - events occurred during LN episodes (1970/71, $1983 / 84)$, while four were configured in EN events (1957/58, 1972/73, 1976/77, 1997/98). Although the classification showed that most of the SACZ+ (SACZ-) events occurred in $\mathrm{LN}(\mathrm{EN})$ years, there are some SACZ+ events associated with EN years and vice-versa. Power spectrum analysis of the PC temporal series indicated that the interannual variability of the precipitation dipole seems to be related to the low-frequency part of ENSO (a peak with a period of 3.5 years) and to the quasi-biennial component of ENSO variability (another peak with a period of 2 years), according to the discussion presented in Mo (2000).

In LN episodes, LN/SACZ - presented stronger negative SST anomalies over Central Pacific and warm anomalies over eastern Indonesia (Fig. 2a). In opposition, negative SST anomalies observed in LN/SACZ+ events are weaker and displaced to the Equatorial East Pacific (Fig. 2b). Moreover, LN events in SACZ+ $(-)$ years presented cold (warm) SST anomalies over Southwestern Atlantic and over Southwestern Indian oceans. The strongest positive Outgoing Longwave Radiation (OLR) anomalies over Central Pacific occurred in LN/SACZ - years, which also presented anomalous convection over Indonesia and the westward displacement of the South Pacific Convergence Zone (SPCZ) (Fig. 2c). LN/SACZ+ years presented weak anomalous convection over eastern Indonesia and over the Austral Subtropical Convergence Zones (Fig. 2d). For LN/SACZ-, the PSAlike wave pattern starts from Central Pacific and also goes to SA (Fig. 2e). A PSA-like wave pattern emanating from Indonesia to SA was observed in LN/SACZ+ events (Fig. 2f).

In EN events, EN/SACZ+ (-) years presented cold (warm) SST anomalies over Southwestern Atlantic (Figs. 3a and $\mathrm{b}$ for EN/SACZ- and EN/SACZ+). Warm SST anomalies over East Pacific were more intense in EN/SACZ years (Fig. 3a). EN/SACZ - years showed the known EN conditions: the convection displaced from Indonesia to Central-East Pacific and the eastward displacement of SPCZ (Fig. 3c). In opposition, EN/SACZ+ years are related to weaker EN conditions: the displacement of the convection from Indonesia to Central Pacific, drought over Southern Africa (Fig. 3d), and a PSA-like wave pattern emanating from Central Pacific towards SA (Fig. 3f). 
(a)

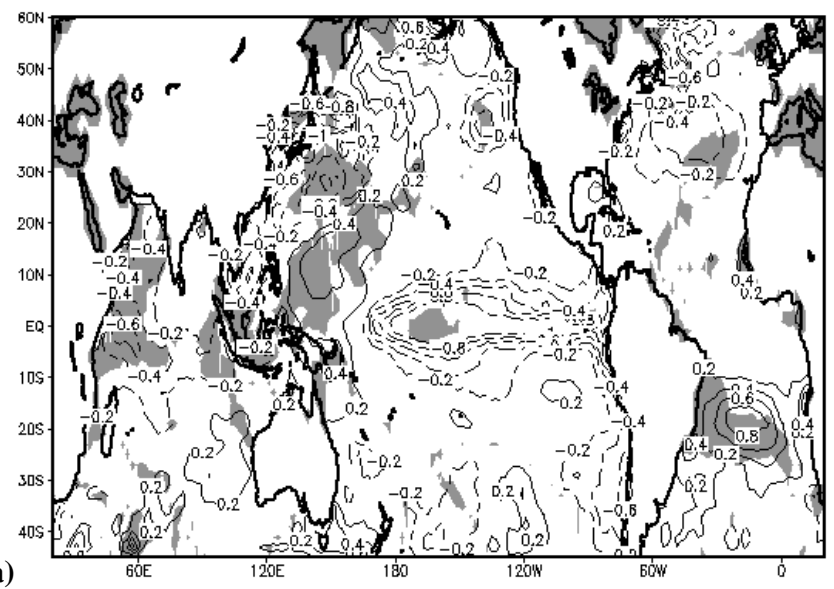

(c)

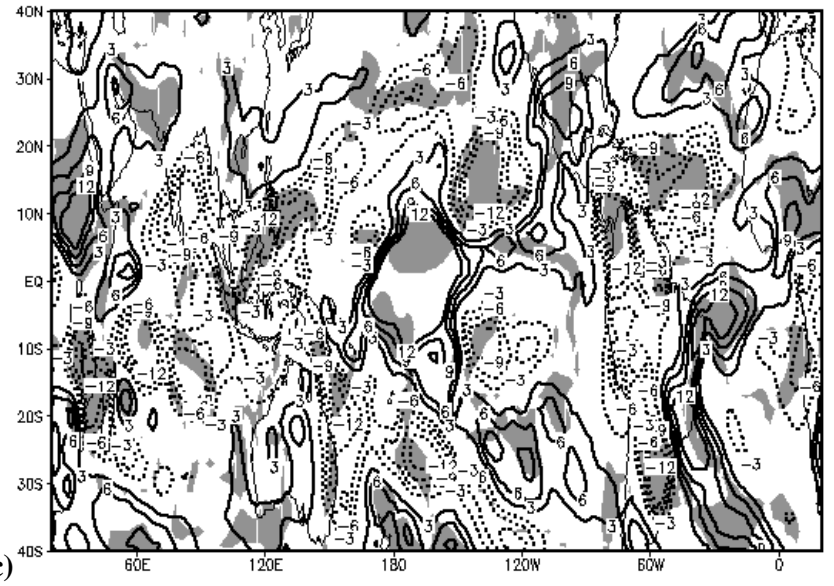

(b)

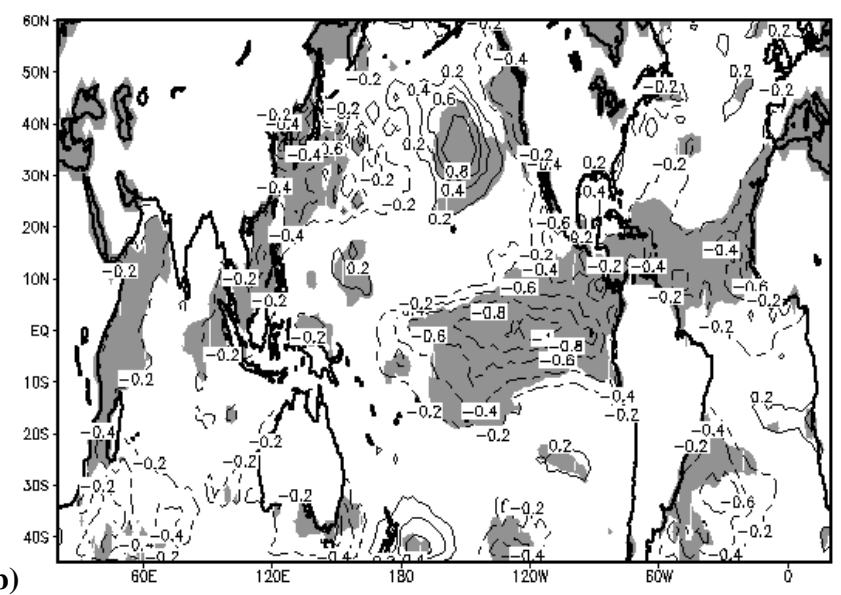

(d)

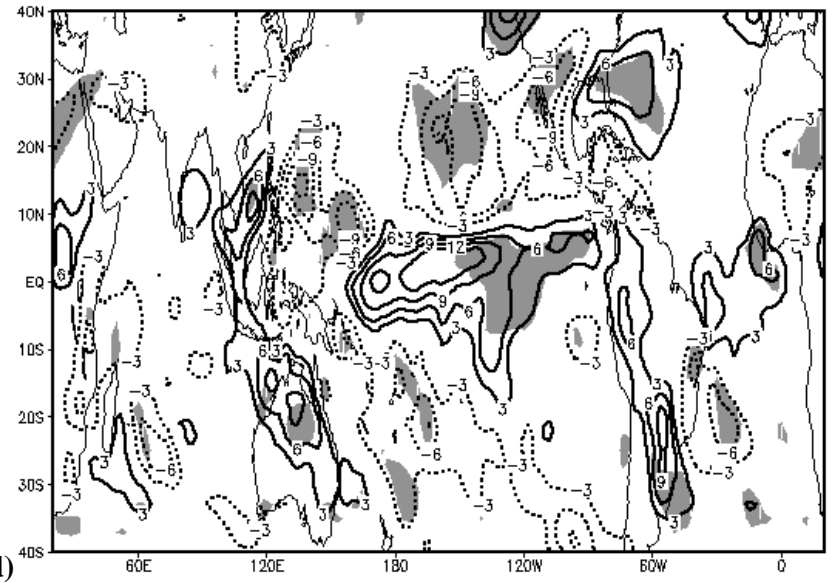

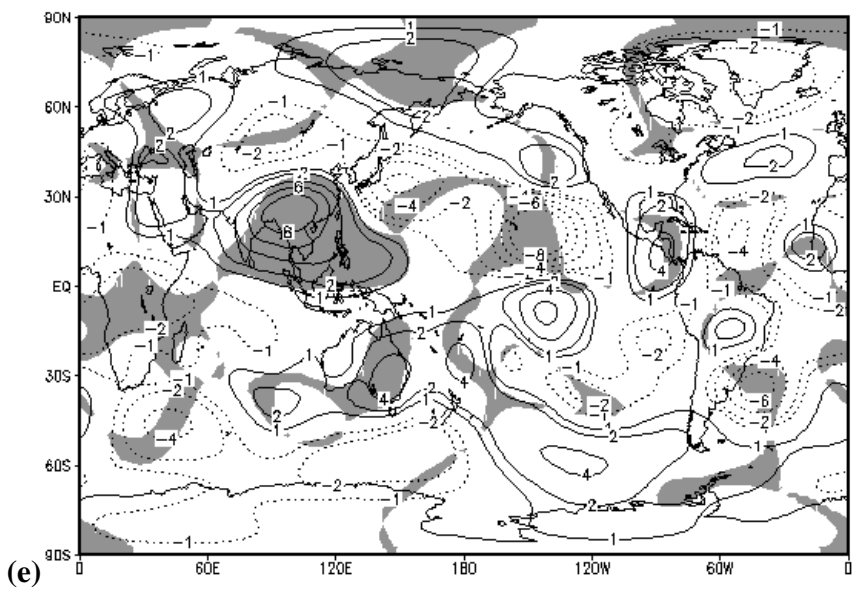

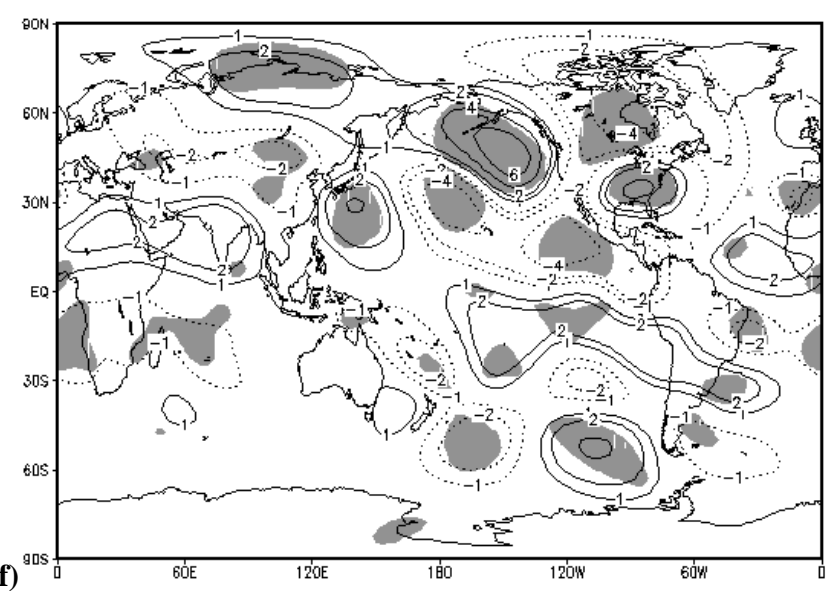

Fig. 2. (a) Composite of DJF SST anomalies $\left({ }^{\circ}\right)$ for the SACZ-/LN episodes; (b) the same as (a), for SACZ+/LN. The interval between the isolines is $0.2^{\circ} \mathrm{C}$; (c) the same as (a), for OLR anomalies $\left(\mathrm{Wm}^{-2}\right)$; (d) the same as (c), for SACZ+/LN. The interval between the isolines is $3 \mathrm{Wm}^{-2}$; (e) the same as (a) for $200 \mathrm{hPa}$ anomalous zonally assimetric streamfunction component $\left(\times 10^{6} \mathrm{~m}^{2} \mathrm{~s}^{-1}\right)$; (f) the same as (e), for SACZ+/LN. The absolute values of the isolines are 0,$5 ; 1 ; 2 ; 4: 6 \times 10^{6} \mathrm{~m}^{2} \mathrm{~s}^{-1}$. The continued (dotted) isolines are associated with positive (negative) anomalies and the shaded areas indicate statistically significant anomalies at the $90 \%$ level.

\section{Conclusions}

This work aims in studying the inter ENSO SST and atmospheric circulation variability related to the low frequency South American dipole precipitation mode of variability
(Paegle and Mo, 2002). REOF analysis was applied over precipitation seasonal anomalies in order to find the dipole mode in the Austral Summer (December to February) and to select the extreme events related to it. These events were classified under the occurrence of ENSO episodes. 
(a)

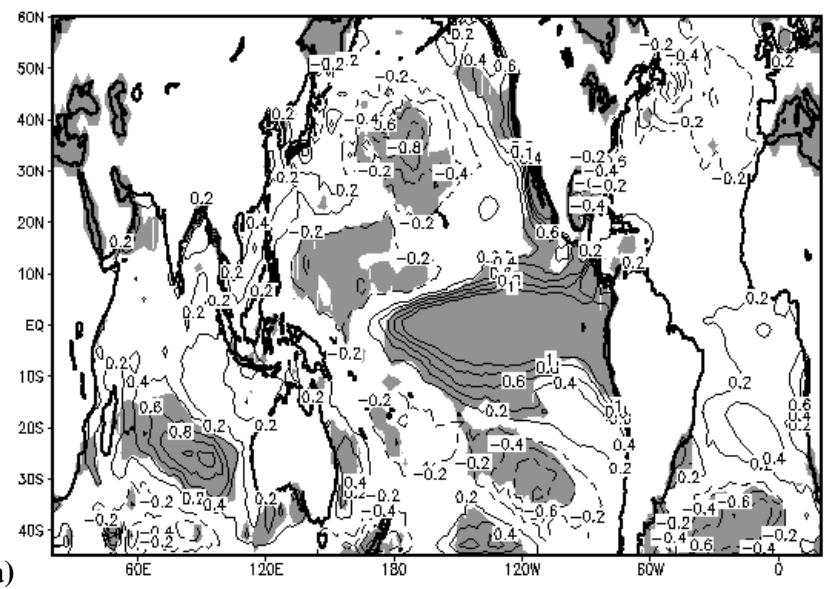

(c)

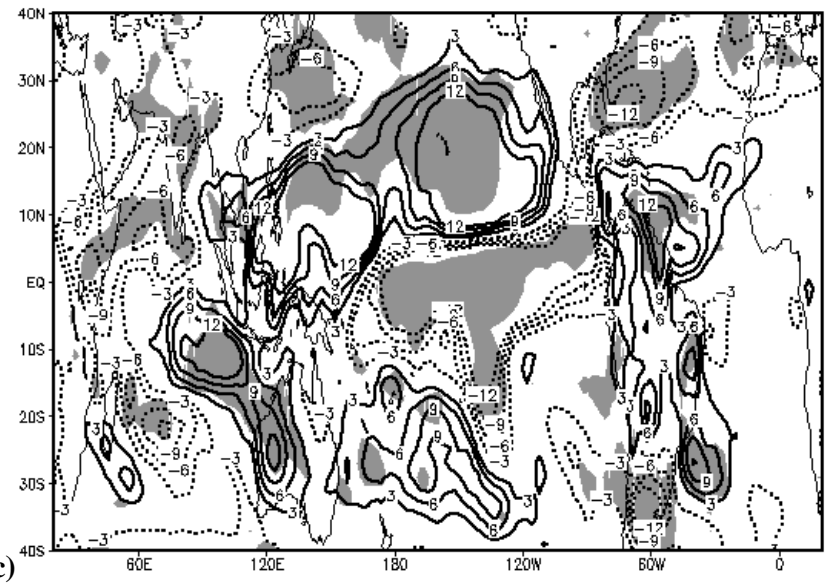

(b)

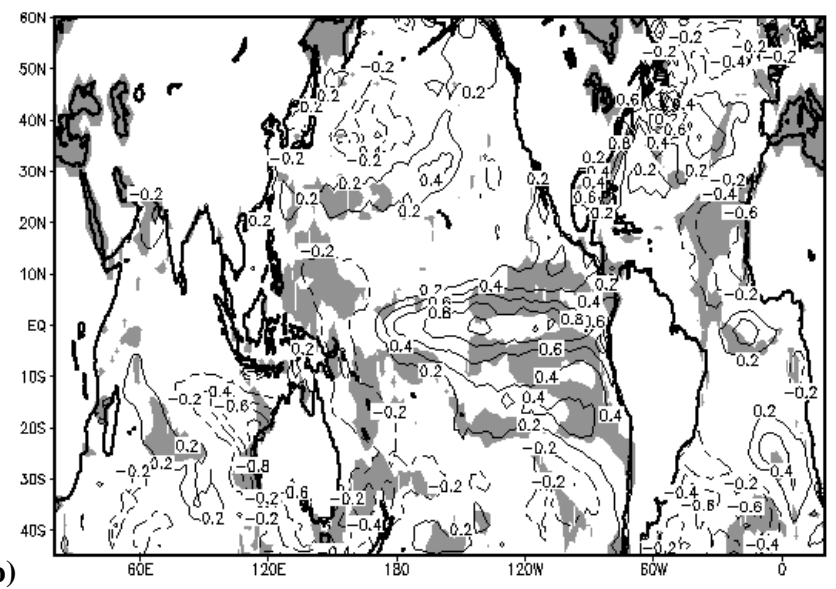

(d)

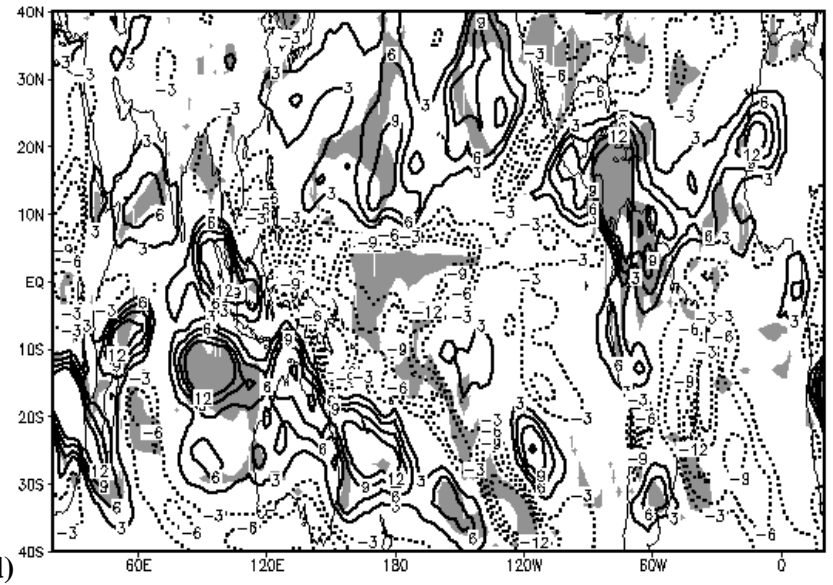

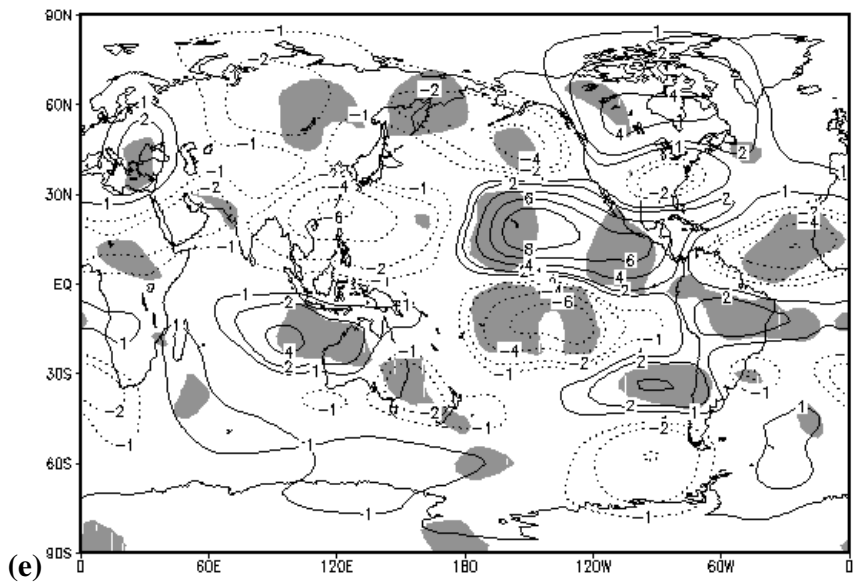

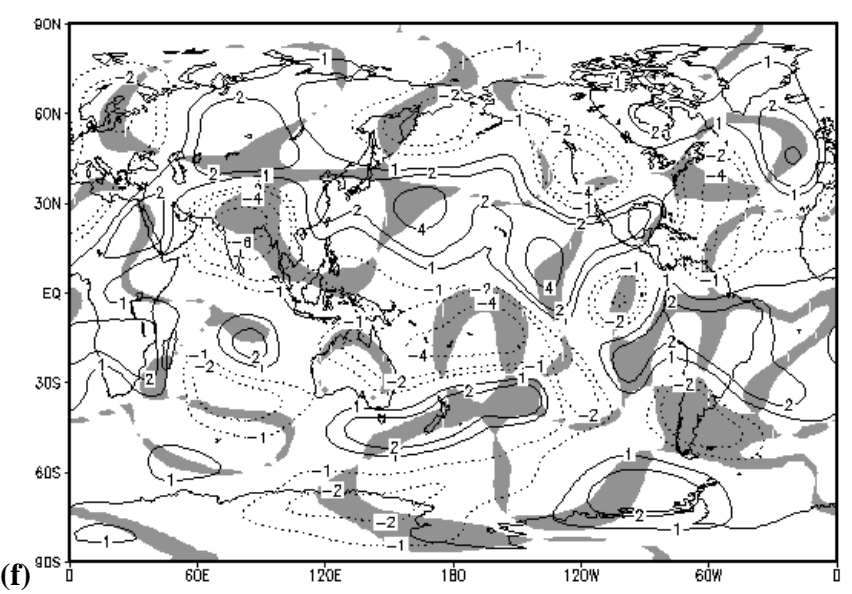

Fig. 3. (a) Composite of DJF SST anomalies $\left({ }^{\circ}\right)$ for the SACZ-/EN episodes; (b) the same as (a), for SACZ+/EN. The interval between the isolines is $0.2^{\circ} \mathrm{C}$; (c) the same as (a), for OLR anomalies $\left(\mathrm{Wm}^{-2}\right)$; (d): the same as (c), for SACZ+/EN. The interval between the isolines is $3 \mathrm{Wm}^{-2}$; (e) the same as (a), for $200 \mathrm{hPa}$ anomalous zonally assimetric streamfunction component $\left(\times 10^{6} \mathrm{~m}^{2} \mathrm{~s}^{-1}\right)$; (f) the same as (e), for SACZ+/EN. The absolute values of the isolines are 0,$5 ; 1 ; 2 ; 4: 6 \times 10^{6} \mathrm{~m}^{2} \mathrm{~s}^{-1}$. The continued (dotted) isolines are associated with positive (negative) anomalies and the shaded areas indicate statistically significant anomalies at the $90 \%$ level.

Power spectrum analysis of the PC temporal series indicated that the interannual variability of the precipitation dipole seems to be related to the low-frequency part of ENSO (a peak with a period of 3.5 years) and to the quasi-biennial component of ENSO variability (another peak with a pe- riod of 2 years). Although the classification of the selected episodes according to the occurrence of ENSO episodes showed that most of the SACZ+ events occurred during LN episodes and the majority of SACZ - events happened in EN episodes, there are some SACZ+ events associated with 
Table 1. Anomalous patterns related to precipitation dipole phases that occurred during La Niña events.

\begin{tabular}{|c|c|}
\hline \multicolumn{2}{|c|}{ La Niña } \\
\hline SACZ- & SACZ+ \\
\hline $\begin{array}{l}\text { Negative SST anomalies over Central Equatorial Pacific and } \\
\text { positive anomalies over Eastern Indonesia; }\end{array}$ & $\begin{array}{l}\text { Weaker negative SST anomalies displaced toward Eastern } \\
\text { Equatorial Pacific and there are no positive anomalies over In- } \\
\text { donesia; }\end{array}$ \\
\hline $\begin{array}{l}\text { Anomalous precipitation over Indonesia and drought condi- } \\
\text { tions over Central Pacific; }\end{array}$ & Anomalous precipitation over Eastern Indonesia; \\
\hline $\begin{array}{l}\text { PSA-like pattern emanating from Central Pacific towards South } \\
\text { America }\end{array}$ & $\begin{array}{l}\text { PSA-like pattern emanating from Indonesia towards South } \\
\text { America }\end{array}$ \\
\hline
\end{tabular}

Table 2. Anomalous patterns related to precipitation dipole phases that occurred during El Niño events.

\begin{tabular}{|c|c|}
\hline \multicolumn{2}{|c|}{ El Niño } \\
\hline SACZ- & SACZ+ \\
\hline Intense EN events; & Weaker EN events; \\
\hline $\begin{array}{l}\text { Convection displaced from Indonesia towards Central-Eastern } \\
\text { Pacific; }\end{array}$ & Convection displaced from Indonesia towards Central Pacific; \\
\hline $\begin{array}{l}\text { PSA-like pattern emanating from Central Pacific towards South } \\
\text { America }\end{array}$ & $\begin{array}{l}\text { PSA-like pattern emanating from Central-Western Pacific to- } \\
\text { wards South America }\end{array}$ \\
\hline
\end{tabular}

EN episodes and vice-versa. The results suggest that the displacement of the convection along the equatorial Pacific ocean can modulate the seesaw pattern over the Southeast of South America. The Tables 1 and 2 summarize the main anomalous patterns observed in both dipole phases during ENSO events.

Acknowledgements. The authors would like to thank the FAPESP in providing financial support through the projects 01/06842-6 and 01/13816-1, CNPq (302459/2002-2), IAI (CRN-055), CIIFEN.

Edited by: P. Fabian and J. L. Santos

Reviewed by: J. L. Santos and another anonymous referee

\section{References}

Chen, M., Xie, P., Janowiak, J. E., and Arkin, P. A.: Global land precipitation: A 50-yr monthly analysis based on gauge observations, J. Hydrometeor, 3(3), 249-266, 2002.

Grimm, A. M., Ferraz, S. E. T., and Gomes, J.: Precipitation anomalies in southern Brazil associated with El Niño and La Niña events, J. Climate, 11, 2863-2880, 1998

Kalnay, E., Kanamitsu, M., Kistler, R., et al.: The NCEP/NCAR 40-year Reanalysis Project, Bull. Amer. Meteo. Soc., 77(3), 437471, 1996.

Mo, K. C.: Relationships between low-frequency variability in the Southern Hemisphere and sea surface temperature anomalies, J. Climate, 13, 3599-3610, 2000.

O’Lenic, E. A. and Livezey, R. E.: Practical Considerations in the Use of REOF Analysis in Diagnostic Studies of Upper-Air Height Fields, Mon. Wea. Rev., 116, 1682-1689, 1988.

Paegle, J. N. and Mo, K. C.: Linkages between summer rainfall variability over South America and sea surface temperature anomalies, J. Climate, 15(12), 1389-1407, 2002.

Reynolds, R. W. and Smith, T. M.: Improved global SST analyses using optimum interpolation, J. Climate, 7, 929-948, 1994.

Trenberth, K. E.: The definition of El Niño, Bull. Amer. Meteo. Soc., 78, 2771-2777, 1997. 